\title{
Formação continuada de professores de Matemática e experiência envolvendo material de Cuisenaire ${ }^{1}$
}

\section{Continuing education of Mathematics teachers and experiment involving material from Cuisenaire}

\author{
Danusa de Lara Bonotto (danusalb@uffs.edu.br) \\ Universidade Federal da Fronteira Sul - Campus Cerro Largo \\ Izabel Gioveli (izabel.gioveli@uffs.edu.br) \\ Universidade Federal da Fronteira Sul - Campus Cerro Largo
}

\begin{abstract}
Resumo:
Este texto apresenta o relato da experiência realizada, utilizando o material de Cuisenaire, com um grupo de professores de Matemática da Educação Básica participantes de um projeto de formação continuada desenvolvido em uma universidade pública do sul do Brasil. O material de Cuisenaire foi utilizado para o estudo e abordagem das operações envolvendo números racionais. De modo específico, textualiza-se neste relato reflexões acerca da influência da formação continuada sobre o trabalho docente. Essas reflexões estão ancoradas num conjunto de sete diários produzidos por uma professora participante do projeto. Observou-se que a formação continuada teve influência sobre o trabalho da professora. Tal influencia manifestou-se nas relações conceituais e metodológicas acerca das operações envolvendo números racionais e nos elementos constitutivos do trabalho docente, especialmente os alunos.
\end{abstract}

Palavras-chave: Formação Continuada; Trabalho docente; Material de Cuisenaire; Números racionais.

\begin{abstract}
:
This text presents the report of the experience, using material from Cuisenaire, with a group of Basic Mathematics teachers participating in a continuing education project developed at a public university in the south of Brazil. The material of Cuisenaire was used for the study and approach of operations involving rational numbers. Specifically, this report reflects on the influence of continuing education on teaching work. These reflections are anchored in a set of seven diaries produced by a teacher participating in the project. It was observed that continuing education influenced the work of the teacher. Such influence was manifested in the conceptual and methodological relations about the operations involving rational numbers and in the constituent elements of the teaching work, especially the students.
\end{abstract}

Keywords: Continuing Education; Teaching work; Cuisenaire material; Rational numbers.

\footnotetext{
${ }^{1}$ Trabalho apresentado na VII Jornada Nacional de Educação Matemática.
} 


\section{INTRODUÇÃO}

Este relato refere-se à utilização do material de Cuisenaire com professores de Matemática atuantes na Educação Básica e participantes de um projeto de extensão desenvolvido por professores vinculados ao Grupo de Estudo e Pesquisa em Ensino de Ciências e Matemática - GEPECIEM. No ano de 2017, os encontros do grupo aconteceram mensalmente na universidade e tiveram duração de aproximadamente três horas. Participaram dos encontros seis professores de Matemática e duas professoras da universidade. Este texto trata de reflexões acerca do trabalho realizado com esse grupo de professores e da influência da formação continuada sobre a prática docente.

No ano de 2017, o grupo de professores estudou sobre a utilização de materiais manipuláveis: material Dourado para a abordagem de produtos notáveis e material de Cuisenaire para a abordagem das operações envolvendo números racionais. Entende-se por material manipulável, todo objeto o qual o estudante seja capaz de sentir, tocar, manipular e movimentar (REYS, 1982 apud VALE, 1999). Nesse sentido, o material Dourado e de Cuisenaire são exemplos de materiais manipuláveis.

Destaca-se que o estudo do material de Cuisenaire foi uma solicitação dos professores participantes da formação continuada para a abordagem das operações envolvendo números racionais: adição, multiplicação e divisão. Neste artigo, utilizam-se os diários produzidos por uma professora participante do projeto para retratar a influência da formação continuada sobre o trabalho docente. A escrita de diários é importante nos processos formativos, pois segundo Alarcão (2010), a escrita do diário é uma estratégia a ser utilizada para desenvolver a capacidade de reflexão e constitui-se em mecanismo para o desenvolvimento pessoal e profissional. Observa-se que o critério para a escolha da referida professora considerou o fato da mesma ter implementado atividades utilizando o material de Cuisenaire com dezoito estudantes do sexto ano do ensino fundamental e ter escrito sobre a sua experiência.

A escrita deste texto está organizada apresentando inicialmente o entendimento de trabalho docente à luz do Interacionismo Sociodiscursivo - ISD de Bronckart (2006, 2008, 2012); na sequência descreve-se sobre o desenvolvimento das atividades utilizando o material de Cuisenaire com os professores e apresentam-se as reflexões decorrentes desse processo. 


\section{O ENTENDIMENTO SOBRE TRABALHO DOCENTE}

A partir dos pressupostos de Bronckart (2012, 2006, 2008), entende-se que o termo agir refere-se a qualquer forma de intervenção orientada de um ou de vários seres humanos. Para esse autor, o trabalho é considerado como uma forma de agir, "como um tipo de atividade ou prática" (BRONCKART, 2006, p. 209) própria da espécie humana, a qual se desenvolve num contexto social específico, por meio das atividades coletivas organizadas.

Para Machado e Bronckart (2009, p. 36-37), apoiados nos aportes da Ergonomia da Atividade, destacando Saujat (2004) e Amigues (2004) e da Clínica da Atividade, em autores como Faïta (2004) e Clot (2007), o trabalho é conceituado como uma atividade que é situada, isto é, realizada em um contexto social específico e em um contexto social mais amplo e possui as seguintes características:

- É pessoal e impessoal. Pessoal, pois envolve as dimensões do trabalhador (física, cognitiva, emocional, etc.) e impessoal, no sentido de que não se desenvolve de forma totalmente livre, dado que as tarefas são prescritas por instâncias externas;

- É interacional, pois a interação é sempre de mão dupla: ao agir sobre o meio, o trabalhador o transforma e é por ele transformado;

- É mediada por instrumentos materiais ou simbólicos, que são artefatos que foram socialmente construídos e apropriados pelo trabalhador para realizar a sua atividade;

- É interpessoal, uma vez que envolve interação com 'o outro', outras pessoas envolvidas direta ou indiretamente, presentes ou ausentes, todos os "outros" interiorizados pelo sujeito.

- É transpessoal, no sentido de que é guiada por 'modelos do agir' construídos pelos coletivos de trabalho em um processo socioistórico.

Assim, Machado e Bronckart (2009) compreendem o trabalho do professor como uma atividade que não é isolada, mas inscrita num contexto socioistórico, inserido em um sistema de ensino e num sistema educacional específico. O esquema da Figura 01 expressa as representações sobre os elementos constitutivos do agir docente e das relações que mantêm entre si. 


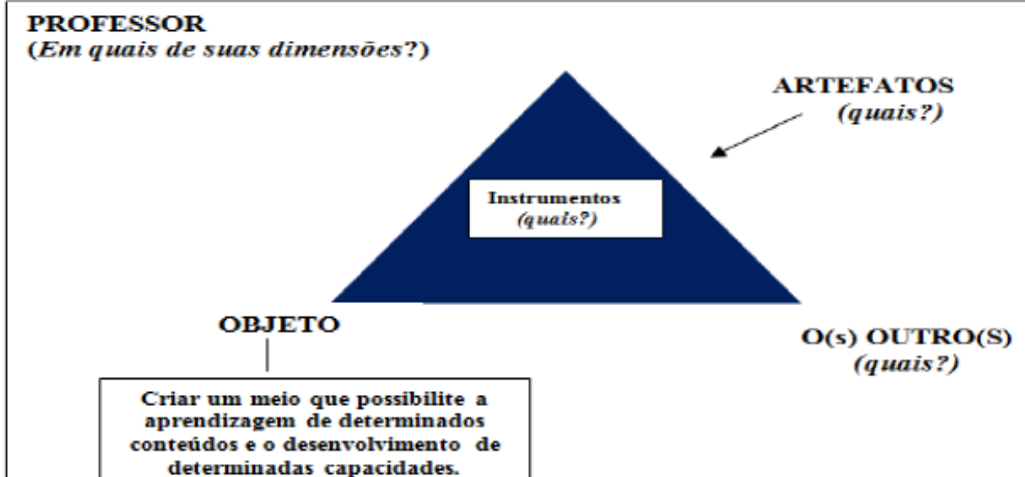

Figura 01 - Esquema do trabalho do trabalho do professor em sala de aula. Fonte: Machado e Bronckart (2009, p. 39).

O esquema, na figura apresentada, expressa que o trabalho do professor em sala de aula,

\begin{abstract}
mobiliza seu ser integral, em suas diferentes dimensões (físicas, cognitivas, linguageiras, afetivas, etc.), com o objetivo de criar um meio propício à aprendizagem de determinados conteúdos e ao desenvolvimento de determinadas capacidades dos alunos. A realização dessa atividade é sempre orientada por prescrições e por modelos do agir, que são apropriados pelo professor e desenvolvidos em interação permanente com a atividade de outros actantes (dos alunos principalmente) e com a utilização de instrumentos materiais ou simbólicos, oriundos da apropriação de artefatos disponibilizados pelo meio social (MACHADO; BRONCKART, 2009, p. 40).
\end{abstract}

Em relação aos termos artefatos e instrumentos, os autores os diferenciam da seguinte forma: o artefato existe fora do sujeito, é neutro e pode ser material (livro, computador, ou outro objeto utilizado), imaterial (programa de computador) ou simbólico (signos, regras, conceitos, metodologias, planos, esquemas). Se o artefato é apropriado pelo sujeito, torna-se, então, instrumento. Por exemplo, os materiais manipuláveis são artefatos materiais. No momento em que o professor os utiliza durante as aulas de Matemática para auxiliar a compreensão de algum conteúdo matemático passa a ser um instrumento. Logo, o artefato se torna instrumento quando serve para realizar a ação do sujeito, neste caso, do professor.

O objeto apresentado na Figura 01, a que se referem os autores, diz respeito à “criação/organização de um meio que seja favorável ao desenvolvimento de determinadas capacidades dos alunos e à aprendizagem de determinados conteúdos a elas correlacionados" (MACHADO; BRONCKART, 2009, p.39). Logo, para construir 
o objeto do seu trabalho, o professor tem à disposição artefatos socioistoricamente construídos e disponibilizados pelo meio social em que se encontra. Nesse viés, os pressupostos teóricos referentes à utilização de materiais manipuláveis se constituem em artefato simbólico. Ao mobilizar tais pressupostos e os implementar na sala de aula para o ensino e aprendizagem de Matemática, o artefato simbólico se torna instrumento para o agir do professor e provoca transformações não apenas sobre o objeto, mas também sobre os outros indivíduos envolvidos na atividade e sobre o próprio professor.

Neste trabalho, a partir das atividades realizadas na formação continuada com o material de Cuisenaire e do registro escrito dos diários de uma professora participante da formação continuada, apresentam-se algumas reflexões acerca da influência do processo formativo sobre os elementos que constituem o trabalho docente.

\section{AS ATIVIDADES REALIZADAS COM OS PROFESSORES}

O estudo sobre o material de Cuisenaire, como mencionado anteriormente, foi sugerido pelos professores participantes do projeto de formação continuada. Esse material, foi criado pelo educador belga Émile Georges Cuisenaire Hottelet (1891-1980) na década de 50, é constituído por barras (em geral de madeira), em formato de prismas quadrangulares, com dez tamanhos diferentes e uma cor diferente para cada tamanho. Nas barras não existem marcações e cada barra pode ser usada para representar um número da base 10 , conforme demonstra a figura, a seguir.

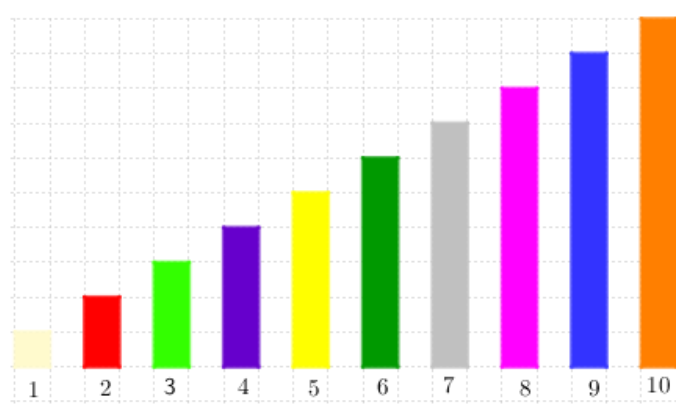

Figura 02 - Representação do material de Cuisenaire. Fonte: Elaborado pelas autoras no GeoGebra² .

${ }^{2}$ O GeoGebra é um aplicativo de matemática dinâmica que combina conceitos de geometria, álgebra e cálculo. Maiores informações em: https://www.geogebra.org/cms/. 
Utilizaram-se cinco encontros, com duração de aproximadamente três horas, para estudos e discussões sobre as operações envolvendo números racionais com a utilização do material de Cuisenaire. Inicialmente aconteceu o reconhecimento do material: identificação das cores aos números correspondentes e a exploração das operações de adição, multiplicação e divisão de números inteiros. Na sequência, utilizou-se a representação de uma fração, entendida como uma relação da parte com o todo, com material de Cuisenaire conforme a figura, a seguir.

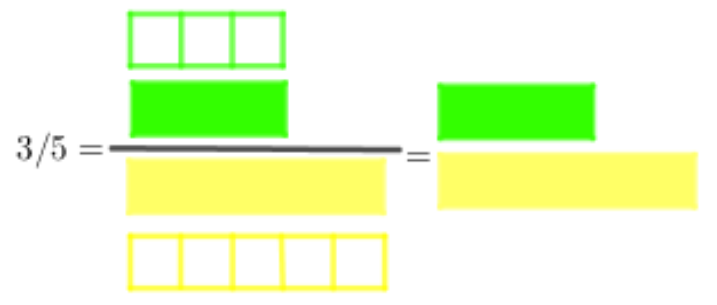

Figura 03 - Representação da fração $\frac{3}{5}$ utilizando o material de Cuisenaire. Fonte: Elaborado pelas autoras no GeoGebra.

A partir da convenção utilizada para representação de frações, realizaram-se atividades como a que segue: quantas barras vermelhas são necessárias para compor uma barra rosa? Escreva uma fração que represente a relação da barra vermelha com a barra rosa. Nesse caso, observa-se que são necessárias quatro barras vermelhas para compor a barra rosa, logo a barra vermelha representa $\frac{1}{4}$ da barra rosa. Pode ser observado também que a barra vermelha é composta por duas barras de cor madeira e, a barra rosa é composta por oito barras de cor madeira. Logo, tem-se que a barra de cor vermelha, também pode representar dois oitavos $\frac{2}{8}$ da barra rosa. Desse modo, tem-se que a fração $\frac{1}{4}$ é equivalente à fração $\frac{2}{8}$, ou seja, $\frac{1}{4}=\frac{2}{8}$. Destaca-se que a partir da realização de atividades como a exemplificada, o conceito de fração equivalente é (re)elaborado e isso foi importante para a realização da operação de adição de números racionais.

$\mathrm{Na}$ sequência, realizaram-se atividades envolvendo adição, multiplicação e divisão de números racionais com o material de Cuisenaire. Apresenta-se, neste texto 
um exemplo envolvendo a adição: Que fração da barra laranja é a barra vermelha? Que fração da barra laranja é a barra amarela? Como podemos representar $\frac{1}{5}+\frac{1}{2}$ ?

Apresentam-se, a seguir, as reflexões decorrentes desse processo formativo. Observa-se que os dados empíricos foram constituídos a partir do registro dos diários de uma professora participante do projeto, a qual (re)organizou as atividades estudadas na formação e implementou em sala de aula com estudantes do sexto ano do nível fundamental de ensino.

\section{REFLEXÕES DECORRENTES DO PROCESSO FORMATIVO}

Nesta seção apresentam-se as reflexões das autoras sobre aspectos dos elementos constitutivos do trabalho docente os quais foram influenciados pela formação continuada. Essas reflexões estão ancoradas nos dados empíricos advindos dos textos da professora e na interlocução teórica sobre o entendimento de trabalho docente, no viés do ISD.

Observou-se a influência da formação continuada provocando transformações nas relações conceituais textualizadas pela professora, no que diz respeito à compreensão dos procedimentos operatórios utilizados nas operações envolvendo números racionais, conforme denotam os segmentos, a seguir.

\section{E se torna mais visível as operações para mim como professora será que para meus estudantes também} será assim? (L25-L27 do Diário 1 - setembro/2017)

Na passagem apresentada anteriormente observa-se que a professora apresenta a utilização do material de Cuisenaire como um artefato que tornou para ela 'mais visível as operações' com números racionais. Além disso, nota-se que a professora textualiza dúvidas em relação à utilização do material com os estudantes para favorecer a compreensão das regras operatórias referentes aos números racionais e isso está marcado no segmento 'será que para meus estudantes também será assim?'. Essa dúvida também denota certa tensão na perspectiva de tornar o artefato (material de Cuisenaire) um instrumento do seu trabalho. Isso também está marcado no segmento 'não me pareceu simplificar e sim complicar' textualizado na passagem, a seguir: 
No início de nosso estudo com as barrinhas de Cuisenaire pensei que nunca usaria com estudantes, não me pareceu simplificar e sim complicar, mas depois de retomado o estudo parece que simplificou o processo. (L23-L25 do Diário 1 - setembro/2017)

Entretanto, após a realização das atividades envolvendo o material de Cuisenaire na formação continuada, a professora textualiza avaliação positiva referente às potencialidades do material para favorecer a abordagem de frações equivalentes e das regras operatórias com números racionais.

O estudo [...] envolvendo as operações com números [...] ampliou o meu conhecimento sobre o assunto. Mostrou uma forma diferente de pensar e representar as frações, de visualizar as frações equivalentes e significar as operações envolvendo frações. (L3-L7 do Diário 7 - dezembro/2017)

O exposto, denota um movimento de (re)configuração referente às relações conceituais envolvendo números racionais e favorecido pelas discussões advindas da formação continuada com a utilização do material de Cuisenaire.

Além disso, nos textos da professora são postos em cena 'outros' actantes envolvidos no trabalho docente: os colegas da escola e os estudantes, conforme denotam as passagens que são apresentadas na sequência, as quais também evidenciam transformações no contexto específico de trabalho da referida professora. Ao transitar da formação continuada para a sala de aula, a professora (re)organiza as atividades realizadas na formação e as adéqua considerando o nível de ensino, o número de estudantes e os seus motivos e intenções. As passagens, a seguir, denotam o exposto.

Preparei um roteiro de atividades a partir do que desenvolvemos nos Ciclos Formativos de Matemática e vamos lá... Os estudantes ainda não trabalharam frações neste ano e vamos começar familiarizando os estudantes com o material, fazer atividades de reconhecimento do material... para na próxima semana realizar atividades específicas de frações com o material.(L8-L12 do Diário 2 setembro/2017)

[...] organizamos os estudantes em três grupos. Cada grupo com uma caixa da escala e cada estudante com uma folha impressa com as atividades [...]. (L3-L6 do Diário 3-setembro/2017)

Os estudantes são postos em cena nos textos dos diários da professora quando ela vislumbra a possibilidade de inserir o material de Cuisenaire ao seu agir docente e ao reconstituir o meio aula, trazendo características específicas do seu contexto de trabalho e do envolvimento dos estudantes no decorrer da realização das atividades conforme denotam as passagens, a seguir. 
Pois é, penso que podemos tentar com os estudantes, [...] então sim vou levar nosso estudo para a sala de aula e observar como será com os estudantes. (L28-L29 do Diário 1 - setembro/2017)

A maioria dos estudantes desenvolveram com facilidade as atividades [...].(L3-L4 do Diário 4 outubro/2017)

Destaca-se que ao reconstituir o meio aula a professora textualiza no seu diário avaliações positivas em relação à utilização do material, as quais permitem identificar transformações especialmente nas relações entre os estudantes e entre os estudantes e a professora.

[... Ifiquei feliz de ver o quanto alguns estudantes se ajudavam, um explicando para o outro o que tinha feito, da maneira como tinha pensado [...] foi bem interessante. (L6-L8 do Diário 4 - outubro/2017)

[...] escreveram sobre como gostaram de trabalhar em grupo onde um ajuda o outro. (L22-L23 do Diário 6-outubro/2017)

[...] é muito gratificante ver os estudantes envolvidos com alegria no desenvolvimento do conteúdo. Acredito que ficou mais significativos os conceito de fração, fração equivalente e adição de frações. (L28-L30 do Diário 6 - outubro/2017)

Conforme Amigues (2004, p. 50), “o objeto da atividade do professor consiste em organizar um meio de trabalho coletivo dos alunos para instaurar neles uma relação cultural com um objeto de conhecimento, a fim de modificar sua relação pessoal com esse conhecimento". Nesse sentido, as avaliações positivas textualizadas nos diários da professora sobre a realização das atividades com os estudantes sinalizam para a satisfação da professora e denotam um movimento de (re)construção da agentividade dos alunos e também da própria professora.

Os colegas da escola também foram actantes postos em cena nos textos dos diários, conforme denotam as passagens, a seguir:

Minha colega Maria ${ }^{3}$ também ficou entusiasmada e como não conhecia a escala de Cuisenaire desenvolveu o roteiro junto com os estudantes, disse ter ficado encantada com uso do material.(L18-L20 do Diário 3 - setembro/2017)

Esta prática também teve aspecto positivo na escola, porque despertou interesse em outros professores dos anos iniciais do ensino fundamental e da educação especial. Estes colegas inclusive solicitaram uma formação para aprenderem a utilizar a Escala Cuisenaire no ensino de frações. (L32L35 do Diário 6 - outubro/2017)

\footnotetext{
${ }^{3}$ Nome fictício, a fim de preservar a identidade da professora.
} 
Diante do exposto, observa-se que ao (re)organizar as atividades realizadas na formação continuada e implementá-las na sala de aula, ou seja, ao inserir no seu contexto específico de trabalho o material de Cuisenaire para explorar a noção e representação de fração, frações equivalentes e as regras operatórias envolvendo a adição de frações além de gerenciar as interações na sala de aula e tentar engajar os estudantes na realização das atividades, há vestígios desse movimento sobre os outros envolvidos no contexto escolar, nesse caso, os colegas da escola. Desse modo, marca-se a influência da formação continuada sobre os elementos constitutivos do trabalho docente: ao transitar da formação continuada para a sala de aula e tornar o artefato simbólico (material de Cuisenaire) um instrumento do seu trabalho, há transformações não apenas sobre o objeto, mas também sobre os outros indivíduos envolvidos na atividade e sobre o próprio professor.

Outro aspecto que merece atenção e está marcado nos textos produzidos pela professora refere-se ao (re)conhecimento do material de Cuisenaire, sua exploração e estudo prévio e a identificação de suas potencialidades e limitações para o trabalho na sala de aula com os estudantes.

A utilização da Escala Cuisenaire no ensino de frações é uma possibilidade positiva, mas requer bastante estudo porque a forma de pensar as operações e desenvolvê-las a partir da escala é nova. (L15L18 do Diário 7 - Dezembro/2017)

A participação no estudo de formação continuada proporcionado pelo Ciclos Formativos em Ensino de Matemática é uma oportunidade ímpar de aprendizado, aperfeiçoamento e desenvolvimento do professor de matemática. Aproxima o professor do ensino regular com o mundo acadêmico proporcionando momentos de estudo especifico da área e possibilidades de desenvolvimento de novas práticas de ensino além da oportunidade de troca de experiências. (L22-L29 do Diário 7 Dezembro/2017)

Destaca-se na passagem acima a valorização pela professora do espaço/tempo constituído pela formação continuada como um espaço de estudo, de pesquisa, de planejamento, de teorização, de criação, de socialização, em que o docente sinta que é importante, que pertence ao grupo constituído e que nele tem voz e é ouvido, aprende e ensina e concomitantemente revê e (re)configura as suas ações.

\section{CONSIDERAÇÕES FINAIS}


O objetivo deste artigo consistiu em relatar a experiência realizada com um grupo de professores de Matemática da Educação Básica, ao utilizar o material de Cuisenaire para o estudo e abordagem das operações envolvendo números racionais, bem como, as reflexões acerca desse movimento formativo sobre os elementos que constituem o trabalho docente. Para tal, utilizou-se o entendimento sobre trabalho à luz do ISD.

A influência da formação continuada sobre o trabalho docente materializou-se nos textos registrados pela professora ao transitar da formação continuada para o seu contexto específico de trabalho, provocando transformações nas relações conceituais e metodológicas acerca das operações envolvendo números racionais, nos outros envolvidos no trabalho docente e na própria professora.

Como perspectiva de continuidade deste estudo, destaca-se a análise dos textos da referida professora à luz dos procedimentos de análise do ISD de Bronckart (2006, 2008, 2012) no que diz respeito aos níveis de análise textual - organizacional, enunciativo e semântico e das figuras do agir de Mazzillo (2006, 2011) para identificação dos tipos de agir quando o professor transita da formação continuada para a sala de aula e torna o artefato material de Cuisenaire um instrumento do seu trabalho.

\section{REFERÊNCIAS}

ALARCÃO, I. Professores reflexivos em uma escola reflexiva. 7. ed. São Paulo: Cortez, 2010.

AMIGUES, R. Trabalho do professor e trabalho de ensino. In: MACHADO, A. R. (Org.) $\mathrm{O}$ ensino como trabalho: uma abordagem discursiva. Londrina: Eduel, 2004. p. 35-53.

BRONCKART, J.P. Atividade de linguagem, textos e discursos: por um interacionismo sócio-discursivo. São Paulo: EDUC, 2012 [edição original: 1999].

BRONCKART, J.P. Atividade de linguagem, discurso e desenvolvimento humano. Campinas: Mercado de Letras, 2006.

BRONCKART, J.P. O agir nos discursos: das concepções teóricas às concepções dos trabalhadores. Campinas: Mercado de Letras, 2008.

CLOT, Y. A função psicológica do trabalho. 2.ed. Petrópolis: Vozes, 2007 [edição original: 1999].

FAÏTA, D. Gêneros de discurso, gêneros de atividade, análise da atividade do professor. In: MACHADO, A. R. (Org.) O ensino como trabalho: uma abordagem discursiva. Londrina: Eduel, 2004. p. 55-80. 
MACHADO, A. R.; BRONCKART, J.P. (Re-)configurações do trabalho do professor construídas nos e pelos textos: a perspectiva metodológica do Grupo Alter-Lael. In: MACHADO, A. R. e colaboradores. Linguagem e Educação: o trabalho do professor em uma nova perspectiva. ABREU-TARDELLI, L. S.; CRISTOVÃO, V. L. L. (orgs). Campinas: Mercado de Letras, 2009. p. 31-77.

MAZZILLO, T. O trabalho do professor de língua estrangeira representado e avaliado em diários de aprendizagem. 2006. 189 f. Tese (Doutorado em Linguística Aplicada e Estudos da Linguagem) - Programa de Estudos Pós-Graduados em Linguística Aplicada e Estudos da Linguagem, Pontifícia Universidade Católica de São Paulo, São Paulo, 2006.

MAZZILLO, T. Analisando textos sobre o trabalho do professor: reflexões sobre uma proposta metodológica. In: MACHADO, A. R.; LOUSADA, E. G.; FERREIRA, A. D.. O professor e seu trabalho: a linguagem revelando práticas docentes. Campinas: Mercado de Letras, 2011. p. 205-234.

SAUJAT, F. O trabalho do professor nas pesquisas em educação: um panorama. In: MACHADO, A. R. (Org.). O ensino como trabalho: uma abordagem discursiva. Londrina: Eduel, 2004. p. 3-34.

VALE, I. Materiais manipuláveis na sala de aula: o que se diz, o que se faz. In: Associação de Professores de Matemática (APM), Actas do ProfMat, (p. 111-120), Lisboa: APM, 1999. 